\title{
Could Disappearance of Endemic (Balkan) Nephropathy Be Expected in Forthcoming Decades?
}

\author{
Ante Cvitkovića Ivana Vuković-Lela ${ }^{b}$ Karen L. Edwards ${ }^{d}$ Sandra Karanovićb

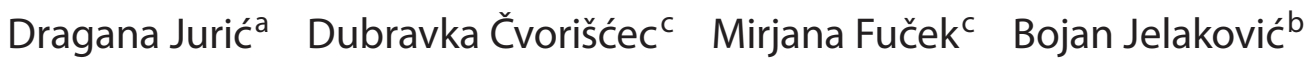 \\ a Institute for Public Health, County Brodsko Posavska, Slavonski Brod, ${ }^{b}$ Department of Nephrology, \\ Arterial Hypertension and Dialysis, School of Medicine, University of Zagreb, and ' Laboratory for \\ Clinical Diagnosis, University Hospital Center, Zagreb, Croatia; ${ }^{\mathrm{d} D e p a r t m e n t}$ of Epidemiology, University of \\ Washington, Seattle, Wash., USA
}

\section{Key Words}

Endemic nephropathy, prevalence $\cdot$ Epidemiology

\begin{abstract}
Background/Aims: An epidemiological survey of endemic nephropathy (EN) was performed in endemic Croatian areas and the current prevalence was compared to that reported for the same villages several decades ago. Methods: A total of 2,487 adult farmers from 6 endemic villages and 3 nonendemic villages were enrolled. An extensive epidemiological questionnaire, clinical examination and laboratory analyses of blood and urine were performed. According to the modified WHO criteria, participants were classified into diseased, suspected of having EN, and those at risk of developing EN. Results: The overall prevalence of EN in the Croatian areas was $1.0 \%$, ranging between 0.3 and $2.3 \%$ in different villages. Those suspected of having EN amounted to $3.9 \%$. In the endemic villages a decreasing trend in the prevalence of EN was observed comparable to the results obtained in previous surveys. It is interesting to note that no EN patients were recorded in the endemic village of Dubočac. Conclusion: The prevalence of EN in the endemic Croatian areas
\end{abstract}

appears to be decreasing. For the first time, we failed to detect any EN patients in a village that was previously considered endemic, which might indicate that EN is diminishing.

Copyright $\odot 2011$ S. Karger AG, Basel

\section{Introduction}

Endemic nephropathy (EN) is chronic tubulointerstitial nephritis with an insidious start and slowly progressive course leading to chronic kidney failure. EN affects a rural population in Bosnia and Herzegovina, Bulgaria, Croatia, Romania, and Serbia. EN cases were recorded in several households, but without a hereditary pattern. Endemic focus in Croatia comprises 14 villages situated near the city of Slavonski Brod in a once inundated and in the past often flooded valley $[1,2]$. According to the census from 2001, the endangered population was 10,865 [3]. Over a 45-year period (1957-2002) EN was the cause of

\section{A.C. and I.V.-L. contributed equally to this work.}

Prof. Bojan Jelaković, MD, $\mathrm{PhD}$

School of Medicine, University of Zagreb

Šalata 3

HR-10000 Zagreb (Croatia)

E-Mail karger@karger.ch $\quad$ Accessible online at:

www.karger.com www.karger.com/kbr
Tel.+385 1238 8271, E-Mail jelakovicbojan@gmail.com 
death for 626 inhabitants from endemic villages $[1,2]$. EN is strongly associated with upper urinary tract transitional cell (urothelial) cancers (UUCs) [1, 2, 4]. Specific mortality from UUC in endemic areas is 55 times higher than in the non-endemic parts of Croatia. A high mortality rate from UUC in endemic areas was reported in several Balkan countries $[2,4,5]$. Numerous hypotheses regarding the etiology of EN and incriminating environmental agents including mycotoxins (ochratoxin A), heavy metals, trace metal deficiencies, and polycyclic aromatic hydrocarbons from coal deposits (Pliocene lignite) have been put forward [6-8]. Recently, chronic ingestion of aristolochic acid, a component of Aristolochia clematitis, was shown to be the causative agent of both chronic tubulointerstitial nephritis and UUC [8-13], thus EN should be considered an environmental form of aristolochic acid nephropathy $[12,14,15]$.

The first systematic field research with an endemic focus on Croatia was conducted in 1957 and, thereafter, research examinations of the endangered population of the endemic villages have continued in order to reveal the etiological agent but also to determine early diagnostic markers and an optimal therapeutic approach enabling us to follow the clinical and epidemiological course of EN and to compare data obtained in the past with results from recent surveys.

According to some authors the prevalence of EN in other endemic areas has remained stable over time and at the same level as it was several decades ago, while others have reported that it was on a significant decrease [1622].

Our aim was to determine the current prevalence of EN in 6 endemic Croatian villages and to compare it with the results obtained in epidemiological studies performed in the same villages several decades ago.

\section{Subjects and Methods}

A total of 2,487 inhabitants from the endemic villages of Slavonski Kobaš, Živike, Pričac, Šumeće, Dubočac and Zbjeg, and the non-endemic villages of Klakar, Donja Bebrina and Rastušje were enrolled in a survey conducted between 2008 and 2010. All adult farmers from those villages were informed in detail and invited to participate on a door-to-door basis. Prior to examination, informed consent was obtained from each participant. After taking a full medical history (including an extended epidemiological questionnaire) and performing a physical examination, fasting blood was drawn and a morning urine specimen was taken. All laboratory analyses were performed in the Laboratory for Clinical Diagnosis, University Hospital Center Zagreb. Urinary $\alpha 1$-microglobulin and albumin concentrations were determined using an immunonephelometric assay (latex-enhanced nephelometry) on a Behring Nephelometer II (Behring Diagnostics GmbH, Marburg, Germany). Values were normalized to urine creatinine. Hemoglobin was determined by electronic counter Cell Dyn 1800. Serum and urine creatinine concentrations were measured by 'continuous' photometry with alkyl pikrat on Olympus AU 2700. The study was approved by the Ethical Boards of the School of Medicine, University of Zagreb, the Croatian National Institute of Public Health and General Hospital 'Dr. Josip Benčević', Slavonski Brod.

The different criteria used across various countries to establish a diagnosis of EN and to classify the endangered population make an exact comparison of the EN prevalence between different endemic areas difficult to achieve [16, 18, 20, 23-28]. In Croatia, the modified WHO criteria have been used for the last 4 decades. Although all these criteria have some serious drawbacks, we have applied them in this study because our aim was to compare the prevalence reported here with results obtained in the past. The modified WHO criteria classify subjects into 4 groups: 'diseased', 'suspected' of having EN, 'at risk' of having EN, and 'others', based on the following diagnostic data: (a) positive family/household history of EN; (b) low molecular weight proteinuria ( $\alpha 1$-microglobulin $>10 \mathrm{mg} / \mathrm{l}$ or $\alpha 1$-microglobulin/creatinine $>14 \mathrm{mg} / \mathrm{g}$ ); (c) serum creatinine $>132.6 \mu \mathrm{mol} / \mathrm{l}$; (d) anemia (hemoglobin $<120 \mathrm{~g} / \mathrm{l}$ if male, $\mathrm{Hb}<113 \mathrm{~g} / \mathrm{l}$ if female), and (e) exclusion of other renal diseases (including diabetes). Subjects were considered 'diseased' if they were positive for ' $a+b+c+d+e$ ', or ' $b+c+d+e$ ', or ' $a+b+d+e$ '; 'suspected' if they had ' $a+b$ ' or ' $b+d$ '; 'at risk' if they were from family/household with EN, and 'others' if they did not comply with any of the above requirements. Routine laboratory tests, imagining techniques (ultrasound, MSCT or MRI) and kidney biopsy were used in order to exclude other types of kidney disease when necessary.

All data were entered into the database and statistical analyses were performed using STATISTICA software, version 9.1. Clinical and laboratory data are reported as the frequency of categorical parameters and as the mean and standard deviation (SD) of continuous variables. Data of subgroups were compared using one-way analysis of variance (ANOVA) for continuous variables with normal distribution and MANOVA for variables with nonnormal distribution. Statistical significance between the subgroups was determined using the $\chi^{2}$ test for discrete variables, and $\mathrm{p}<0.05$ was considered significant. The number of inhabitants from every village was determined according to the census of 2001. The prevalence of EN patients was calculated and expressed as a percentage of the total number of eligible inhabitants of endemic villages.

\section{Results}

The overall participation rate in this survey was $91 \%$ of the eligible adult inhabitants. These 6 villages represent $42.8 \%$ of the villages in endemic areas in Croatia. A diagnosis of EN was established in 33 subjects (14 males, 19 females), and as shown in table 1 the overall prevalence of EN is $1.0 \%$, and 130 participants (3.9\%) were classified 
Table 1. Prevalence of diseased subjects, those with suspected EN, and those at risk of EN

\begin{tabular}{lccrrr}
\hline Village & $\begin{array}{l}\text { Total number } \\
\text { of inhabitants }\end{array}$ & $\begin{array}{l}\text { Enrolled farmers } \\
\mathrm{n}(\%)\end{array}$ & $\begin{array}{l}\text { Diseased } \\
\mathrm{n}(\%)\end{array}$ & $\begin{array}{l}\text { Suspected EN } \\
\mathrm{n}(\%)\end{array}$ & $\begin{array}{l}\text { At risk of EN } \\
\mathrm{n}(\%)\end{array}$ \\
\hline Slavonski Kobaš & 1,303 & $751(57.6)$ & $24(1.8)$ & $85(6.5)$ & $165(12.7)$ \\
Živike & 308 & $125(40.6)$ & $1(0.3)$ & $10(3.2)$ & $18(5.8)$ \\
Pričac & 132 & $63(47.7)$ & $3(2.3)$ & $6(4.5)$ & $13(9.8)$ \\
Šumeće & 610 & $435(71.3)$ & $3(0.5)$ & $12(1.9)$ & $39(6.4)$ \\
Dubočac & 282 & $177(62.8)$ & 0 & $5(1.8)$ & $15(5.3)$ \\
Zbjeg & 510 & $343(67.3)$ & $2(0.4)$ & $5(0.9)$ & $17(3.3)$ \\
Total EN villages & 3,145 & $1,894(60.2)$ & $33(1.0)$ & $123(3.9)$ & $267(8.5)$ \\
Klakar $^{2}$ & 290 & $149(51.4)$ & 0 & $1(0.3)$ & 0 \\
Donja Bebrina & $228(48.6)$ & 0 & $5(1.1)$ & $2(0.4)$ \\
Rastušje $^{2}$ & 469 & $216(77.4)$ & 0 & $1(0.4)$ & $2(0.7)$ \\
\hline
\end{tabular}

${ }^{1}$ According to 2001 census. ${ }^{2}$ Control, non-endemic villages.

as suspects for EN (63 males, 67 females). Gender distribution was not significantly different between diseased subjects and those suspected of having EN versus those at risk of having EN as well as versus others $(p=0.062)$ and farmers from non-endemic villages $(p=0.191)$. Diseased subjects and those suspected of having EN were significantly older than those at risk, others and farmers from non-endemic villages $(74.1 \pm 7.7$ and $59.9 \pm 16.2$ years of age vs. $47.2 \pm 15.6,50.3 \pm 17.5,53.3 \pm 17.1$ years of age, respectively; $\mathrm{p}<0.0001)$ and consequently, they spent the longest period of life in their villages (70.8 \pm 10.2 vs. $55.5 \pm 19.3$ years, $41.3 \pm 17.4,39.6 \pm 21.2$ and $42.5 \pm 21.4$ years, respectively; $\mathrm{p}<0.0001)$. There were no differences in duration of living in the same village between those at risk, others and farmers from control villages $(p=0.051)$. None of the farmers from non-endemic villages was classified as diseased. However, we have identified 7 suspected ( 3 men, 4 women) and 4 at risk of developing EN (4 women) in non-endemic villages.

In endemic villages the prevalence of diseased subjects ranges between 0 and $2.3 \%$. For the first time no farmer was found to have EN in 1 endemic village (Dubočac). The prevalence of suspected and those at risk in endemic villages ranges between 0.9 and $6.5 \%$ and 3.3 and $12.7 \%$, respectively. In non-endemic villages, the prevalence of those suspected of having EN and those at risk ranges between 0.3 and $1.3 \%$ and 0 and $0.7 \%$, respectively.

The prevalence of EN in endemic Croatian villages has decreased during the last 4 decades. In 1977, the highest prevalence rate of $8.3 \%$ was recorded in the village of Pričac. In this survey, the prevalence rate remained the highest in this village but it had decreased to $2.3 \%$. A de- creasing trend is present in all other endemic villages. In surveys performed in the 1970s and 1980s, the prevalence of disease was $2.4,1.9,0.8,2.0$ and $0.4 \%$ in the villages of Slavonski Kobaš, Šumeće, Zbjeg, Dubočac and Živike, respectively.

\section{Discussion}

For many decades, the prevalence of EN remained stable and approximately the same in the majority of endemic areas. However, over the past several years, diverse and even opposite data on prevalence have been reported in several countries harboring EN [3, 16-20,22, 29]. This could suggest that disease activity differs between endemic foci implying that an environmental agent is still very present in some endemic areas, while decreasing or absent in others. Alternatively, the differences in prevalence observed in different countries could also be due to the use of different diagnostic criteria [24-28], differences in case fatality or duration of disease. In the past, the prevalence of EN in Croatia was in concordance with the majority of the results obtained in other endemic areas ranging between 0.4 and $8.3 \%[1,3,30]$ with an average of $4.9 \%$ (data on record in the Public Health Institute, Slavonski Brod). Since we aimed to compare recent results with data obtained several decades ago, and to present the dynamics of the prevalence trends over a period of time, we have applied the criteria used in the past being aware that present day diagnosis and classification of EN should be made using more reliable and more accurate diagnostic tools and cutoffs. The results of this survey 
confirmed that EN has not disappeared and is still present in the endemic areas of Croatia. However, we have identified important new facts which should be taken into account when making projections and plans for healthcare in this area and also when discussing the etiology of this disease.

Firstly, we have observed a trend that suggests a decrease in the prevalence of confirmed cases of EN in the EN villages included in this survey which is in agreement with the reports of other authors $[19,20]$. The same trend was observed for those suspected cases of EN. In our study, the prevalence of suspected EN cases ranged from 0.9 to $6.5 \%$, while in studies conducted between 1976 and 1987 it ranged between 11.6 and 27.3\% [31]. Our observation that the mean age has shifted to the older decades is again in accordance with other reports $[16,17,31]$. In the period 1960-1990 the average age of EN patients was 44.5 years and after 1990 the average age was 61.9 [3]. Women were slightly, but not significantly, more affected than men. The same was confirmed in this survey, again with a marked shift toward older age groups. Both facts indicate that the environmental agent is less active than in the past. The decreased prevalence could be due either to a decrease in incidence and/or that people with the disease are dying. The possibility that the prevalence has a decreasing trend due to case fatality could be ruled out because we and others $[15,16,31]$ have observed a shift of the disease to older ages. So, in fact those with the disease or suspect of having EN are living longer today than in the past [2]. If exposure to the environmental agent has decreased or been eliminated, then it could be assumed that, over the next several decades, EN would disappear from this area. This presumption is supported by results obtained in the endemic village of Dubočac. In this endemic village, the EN prevalence of 2\% in 1985 was higher than the overall prevalence of EN observed over the entire Croatian EN area in this most recent survey. However, in 2010, none of enrolled farmers from the village of Dubočac was diagnosed as an EN patient, and the number of suspected EN cases in this village was the smallest in the whole region. It is questionable whether this might be due to the fact that diseased subjects were not participating or those with EN died faster. However, all inhabitants were invited to participate, they all were examined in their homes and all members of previously identified positive EN families and households were enrolled. The participation rate was the same as in the surveys organized several decades ago when the same criteria were applied as in this study. The average age at death in this village is not different from other villages. As none of the diseased subjects moved out of this village, it is obvious that all EN patients from this village had died. Furthermore, a decrease in prevalence could not be explained by the diluting effect of immigrants from non-endemic areas. In the past 25 years only 30 immigrants have settled in this village ( 5 from non-endemic Bosnian villages, and 16 from non-endemic and 9 from endemic Croatian villages). In field survey we failed to diagnose any new case and, moreover, during the past 10 years none of the patients from the village of Dubočac starting dialysis has been diagnosed with EN (data on record from the General Hospital Slavonski Brod). Čukuranović et al. [19] found that the number of EN patients in the terminal phase as well as the number of EN patients with UUC is decreasing in south Serbia. This is in line with results from Bulgaria, and Dimitrov et al. [20, 22] raised the question whether EN would disappear. Gluhovschi et al. [18] reported that in recent years there have been no newly reported EN patients from the Caras-Severin foci in Romania. Recently, a group from Lazarevac, Serbia, reported that time trends in EN incidence suggest that the disease has not yet disappeared in the Kolubara region of Serbia [16]. They observed a nonsignificant increase in the period 1989-2009 and most a plausible explanation for this trend was given by the authors who commented that the increasing trend was a result of more vigorous screening and monitoring of EN over the last decade in comparison to the earlier period. Janković et al. [16] also found that in the youngest age group (20-44 years) the EN incidence rates were lower, but in the oldest age group (65+ years) significantly higher. These data are in concordance with our results on time trends of prevalence, and our conclusion that EN is still present, but new cases would only be diagnosed only in the elderly who in the past were exposed to the environmental risk factor for a long period of their lives. They had a slower clinical course and kidney damage became manifest in advanced ages. The difference among various endemic foci could result, as already mentioned, from the use of different diagnostic criteria, or might reflect differences in activity of the environmental toxic agent. Our recent studies clearly demonstrate that in Bosnia and Herzegovina, Croatia and Serbia, aristolochic acid is a causative agent $[8-11,13]$. Information on the decreasing number of EN patients is important for public health authorities and for future projections as it could be presumed that the need for renal replacement therapy, at least due to EN, would be reduced in this region. Although the prevalence of EN is lower, a substantial number of diseased patients and those suspected of having EN is still present in the Croa- 
tian endemic area. Screening of those at risk of developing EN and/or UUC, i.e. members of the households with registered cases, is still mandatory.

Secondly, we have detected several cases suspected of having EN and those at risk of developing EN in the villages outside a previously determined EN area. This is in line with the results of Nikolić et al. [32] who observed a higher UUC prevalence not only in the established Serbian endemic areas but also in the surrounding villages. The same was observed by other authors [29]. Very probably in the past, those cases were unrecognized. Thus, EN might have been under-diagnosed and some of the patients classified as unknown end-stage renal diseases in the national registries were in fact EN patients. This was a consequence of the established, almost dogmatic belief that EN could be diagnosed only in strongly restricted areas, and some diagnostic criteria even disable making a diagnosis of EN in such cases [28]. EN should be considered as part of the differential diagnosis in all rural patients classified as end-stage renal disease of unknown origin as well as in all UUC patients from rural areas not only in this part of Europe, but worldwide. However, this observation should be confirmed using more accurate diagnostic criteria.

Based on our results it can be concluded that EN is still present in the endemic area of Croatia and that screening of the endangered population is justifiable and necessary. Although this might seem inconsistent with our finding of a decrease in prevalence, it should be kept in mind that $\mathrm{EN}$ is characterized by slow onset. Regular examinations of those at risk who might develop the disease in forthcoming years are important regardless of whether or not they are currently exposed to the environmental agent.
The observed decrease in prevalence could indicate that the environmental agent is less active or even not active at all. This is in line with our previous results which showed that aristolochic acid is the main risk factor and causative agent of EN [8-11, 13, 15]. In the last few decades, exposure to this strong environmental nephrotoxin and carcinogen has decreased due to the significant improvement in farming and milling practices, disabling and preventing the contamination of flour. The decreased trend in prevalence and the shift in age of the diseased and suspected subjects to older ages indicate that further diminishing and even disappearance of EN could be expected within the next 15 years. Our finding of the presence of suspected EN cases in the established endemic area is also important as it raises an intriguing question as to whether some EN cases have been under-diagnosed in the past, thus contributing to underestimation of the true prevalence and distribution of disease. Today, EN should be excluded in all end-stage renal disease patients, particularly from rural areas, before being classified as an unknown renal disease.

\section{Acknowledgements}

This work is supported by Fogarty International Collaboration Award (FIRCA) number R03TW007042, award number P01ES004068 from the National Institute of Environmental Health Sciences, and grants 108-0000000-0329 and 098-0982464 from the Ministry of Science, Education and Sports of the Republic of Croatia.

The authors would like to thank Arthur P. Grollman, MD, for suggestions and critical review of the manuscript and Ninoslav Leko, MD, for providing us with information from the Dialytic Unit, General Hospital, Slavonski Brod.

\section{References}

1 Čeović S, Miletić-Medved M: Epidemiological features of endemic nephropathy in the focal area of Brodska Posavina, Croatia; in Čvorišćec D, Čeović S, Stavljenić-Rukavina A (eds): Endemic Nephropathy in Croatia. Academia Croatica Scientiarum Medicarum. Zagreb, Medicinska naklada, 1996, pp 7-21.

2 Miletić-Medved M, Domijan AM, Peraica M: Recent data on endemic nephropathy and related urothelial tumors in Croatia. Wien Klin Wochenschr 2005;117:604-609.

-3 Miletić Medved M, Jelaković B, Bistrović D, Leko N, Marić Z: Epidemiološke osobitosti endemske nefropatije u Hrvatskoj 2005. godine. Acta Med Croat 2007;61:141-148.
4 Stefanović V, Radovanović Z: Balkan endemic nephropathy and associated urothelial cancer. Nat Clin Pract Urol 2008;5:105112.

-5 Belicza M, Demirović A, Tomić K, Lenicek T, Pavić I, Jakovina K, Vukelić M, Jakovina T, Mišić M, Krušlin B: Comparison of occurrence of upper urinary tract carcinomas in the region with endemic villages and nonendemic nephropathy region in Croatia. Coll Antropol 2008;32:1203-1207.

6 Long DT, Voice TC: Role of analysis in solving the mystery of Balkan endemic nephropathy. Croat Med J 2007;48:300-311.
7 Voice TC, Long DT, Radovanović Z, Atkins JL, McElmurry SP, Niagolova ND, Dimitrov P, Petropoulos EA, Ganev VS: Critical evaluation of environmental exposure agents suspected in the etiology of Balkan endemic nephropathy. Int J Occup Environ Health 2006; 12:369-376

$\checkmark 8$ Grollman AP, Jelaković B: Role of environmental toxins in endemic (Balkan) nephropathy. J Am Soc Nephrol 2007;18:2817-2823.

-9 Grollman AP, Shibutani S, Moriya M, Miller F, Wu L, Moll U, Suzuki N, Fernandes A, Tosenquist T, Medverec Z, Jakovina K, Brdar B, Slade N, Turesky RJ, Goodenough AK, Rieger R, Vukelić M, Jelaković B: Aristolochic acid and the etiology of endemic (Balkan) nephropathy. Proc Natl Acad Sci USA 2007;104:12129-12134. 
-10 Hranjec T, Kovač A, Kos J, Mao W, Chen JJ, Grollman AP, Jelaković B: Endemic nephropathy. The case for chronic poisoning by aristolochia. Croat Med J 2005;46:116125.

- 11 Slade N, Moll UM, Brdar B, Zorić A, Jelaković B: p53 mutations as fingerprints for aristolochic acid - an environmental carcinogen in endemic (Balkan) nephropathy. Mutat Res 2009;663:1-6.

12 Debelle FD, Vanherweghem JL, Nortier JL: Aristolochic acid nephropathy: a worldwide problem. Kidney Int 2008;74:158-169.

-13 Moriya M, Slade N, Brdar B, Medverec Z, Tomić K, Jelaković B, Wu L, Truong S, Fernandes A, Grollman AP: TP53 Mutational signature for aristolochic acid: an environmental carcinogen. Int J Cancer 2011;129: 1532-1536.

- 14 Cosyns JP, Jadoul M, Squifflet JP, De Plaen JF, Ferluga D, Van Ypersele de Strihou C: Chinese herb nephropathy. A clue to Balkan endemic nephropathy. Kidney Int 1994;45: 1680-1688.

-15 Grollman AP, Scarborough J, Jelaković B: Aristolochic acid nephropathy: an environmental and iatrogenic disease. Adv Mol Toxicol 2009;3:211-227.

-16 JankovićS, Bukvić D, Marinković J, Janković J, Marić I, Djukanović L: Time trends in Balkan endemic nephropathy incidence in the most affected region in Serbia,1977-2009:the disease has not yet disappeared. Nephron Dial Transplant 2011;26:3171-3176.
7 Bukvić D, Marić I, Arsenović A, Janković S, Djukanović L: Prevalence of Balkan endemic nephropathy has not changed since 1971 in the Kolubara region in Serbia. Kidney Blood Press Res 2007;30:117-123.

18 Gluhovschi G, Margineanu F, Velciov S, Gluhovschi C, Bob F, Petrica L, Bozdog G, Trandafirescu V, Modalca M: Fifty years of Balkan endemic nephropathy in Romania: some aspects of the endemic focus in the Mehedinti county. Clin Nephrol 2011;75:34-38.

19 Čukuranović R, Petrović B, Čukuranović Z, Stefanović V: Balkan endemic nephropathy: a decreasing incidence of the disease. Pathol Biol (Paris) 2000;48:558-561.

20 Dimitrov PS, Simeonov VA, Stein AD: Balkan endemic nephropathy in Vratza, Bulgaria, 1964-1987: an epidemiologic analysis of population-based disease registers. Eur J Epidemiol 2001; 17:847-853.

21 Imamović G, Trčević S, Mesić E, Stipančić $\check{Z}$ : Endemic (Balkan) nephropathy in Bosnia and Hercegovina: current status. Coll Antropol 2006;30(suppl1):41.

-22 Dimitrov PS, Simeonov VA, Ganev VS Karamaus WJ: Is the incidence of Balkan endemic nephropathy decreasing? Pathol Biol (Paris) 2002;50:38-41.

23 Čvorišćec D, Čeović S, Boršo G, Rukavina AS: Endemic nephropathy in Croatia. Clin Chem Lab Med 1998;36:221-227.

24 Kettner H: The endemic nephropathy of south-eastern Europe. Bull World Health Organ 1965;32:431-438.

-25 Djukanović L, Marić I, Marinković J, Ignjatović J, Ignjatović J, Bukvić D: Evaluation of criteria for the diagnosis of Balkan endemic nephropathy. Renal Fail 2007;29: 607-614.
26 Djukanović L, Marinković J, Marić I, Ležaić V, Dajak M, Petronić D, Matić M, Bukvić D: Contribution to the definition of diagnostic criteria for Balkan endemic nephropathy. Nephron Dial Transplant 2008;23:39323938.

27 Stefanović V, Jelaković B, Čukuranović R, Bukvić D, Nikolić J, Lukić LJ, Gluhovschi G, Toncheva D, Polenaković M, Cosyns JP: Diagnostic criteria for Balkan endemic nephropathy: proposal by an international panel. Renal Fail 2007;29;867-880.

28 Danilović V: Endemic nephropathy in Yugoslavia; in Strahinjić S, Stefanović V (eds): Endemic (Balkan) Nephropathy. Proceedings of the 4th Symposium on (Balkan) Nephropathy, Niš, 1979. Niš, Inst Nephr Haemod, 1981, pp 1-5.

-29 Marković N, Ignjatović I, Čukuranović R, Petrović B, Kočić B, Stefanović V: Decreasing incidence of urothelial cancer in a Balkan endemic nephropathy region in Serbia. A surgery based study from 1969 to 1998. Pathol Biol (Paris) 2005;53:26-29.

30 Čeović S, Pleština R, Miletić-Medved M, Stavljenić A, Mitar J, Vukelić M: Epidemiological aspects of Balkan endemic nephropathy in a typical focus in Yugoslavia. IARC Sci Publ 1991;115:5-10.

31 Čeović S, Hrabar A, Radonić M: Proširenost, učestalost i druge epidemiološke značajke balkanske endemske nefropatije u Brodskoj posavini. Anali Zavoda Jugoslav Akad 1985; 4:373-385.

32 Nikolić J, Djokić M, Ignjatovic I, Stefanovic $\mathrm{V}$ : Upper urothelial tumors in emigrants from Balkan endemic nephropathy areas in Serbia. Urol Int 2006;77:240-244. 